\title{
Research on application of Chinese culture in animated movie KungFu Panda \\ WeiPeng Wang
}

School of art,Zhengzhou University of Industry Technology,Zhengzhou451100,China.

451509647@qq.com

Keywords: KungFu panda;Animated movie;Chinese culture;Application research

\begin{abstract}
The key to Successful the film Kungfu Panda is carefully analyzed the Chinese culture and closely related to the hot spot of mixed culture in the context of globalization, through the exact expression of Chinese and western culture give a thought to the development Chinese animation. This paper based on the film Kungfu Panda to analysis the application of Chinese culture in the film and put forward a new train of thought for Chinese animation in discover and use their native culture. Chinese animation not only need to enhance the level of technology, but also on the connotation of ascension, Chinese animation re-emergence in the world animation stage must be use this national culture.
\end{abstract}

\section{Introduction}

The success of the kung fu panda is fusion the Chinese culture and western culture, two kinds of culture blend in the film and mutual influence, each retain the original cultural charm. The cultural characteristics reflects in the film is a new building of western society on Chinese culture and interpretation, whether the understanding of the surface or deep cognition,it is no denying that Chinese culture used in the creation of the cartoon is successful, that is why it is popular with the audience in China[1].This article based on the application of Chinese culture in the film as a research topic, analysis the Chinese culture in character design, scene design, cultural background, and music design.

\section{Chinese culture and character design}

China is a civilization with a history of 5000, Chinese culture is rich and colorful,the main image design including the dragon, turtle and panda, and has a strong Chinese art performance in kungfu Panda.This film treat panda as leading role bear the lazy character, round shape lifelike.In the film, golden monkey, the snake spirit, mantis, dumpling tiger, cranes are used for the five image personified as tigers and monkeys, snakes, mantis crane to express, and these roles are more representative of different cultures show different modelling design. The dragon is the symbol of hero in Chinese mythm,it represents the national temperament of the Chinese nation, Po who is the dragon warrior is also the Chinese cultural interpretation. The tortoise in Chinese culture is associated with longer life and wisdom, master Wugui is the representative of the wise and the word he said contain with Chinese buddhist thought[2].

Clothing and props also embodies the Chinese culture,the cloth- shoes which wear by Po is classic; the master Wugui is wearing robes of Buddhism; the teacher raccoon is wearing a dress of Taoism in china; the tiger is wearing uniforms of Kongfu in china;Cranes as the custodian of the big five, he was wearing a hat and belt on the leg means that he study hard and it is the image of Chinese martial arts, each person's clothing is contains with Chinese cultural background. In terms of props, knives, spears, clubs, chopsticks, noodles and dumplings used by characters is the traditional Chinese which are close to the Chinesepeople's daily, it is these lifelike characters with Chinese temperament are popular with the people of the world.

\section{Chinese culture and scene design}


Animation scene is a scene of animation role performance, animation scene not only provide the place of performance for animated characters but also have the effect to foil atmosphere,and reaction time background, animation scene is the product of animation designers through the art processing, different animation background response of different regional style.the architectural has a strong Chinese style in kungfu Panda, emerald palace which is the important scenes in the film hide in the mountains like a fairyland, this location is the same with Chinese temples which on the top of a high or scenic mountainside,that embodies the Taoist culture of quietism. The appearance of the emerald palace is same with the palace of China which is golden glazed tile, bright red big pillars and Windows with distinctive features,that reflects the style of Chinese classical architecture,the internal decoration of emerald palace based on five phases reflects the magnificent palace in ancient china. Another important scene which named Peace Valley that buildings like the ancient Chinese architecture, the other building such as temple, memorial arch, palace will be take the western audiences into china's ecological environment[3].

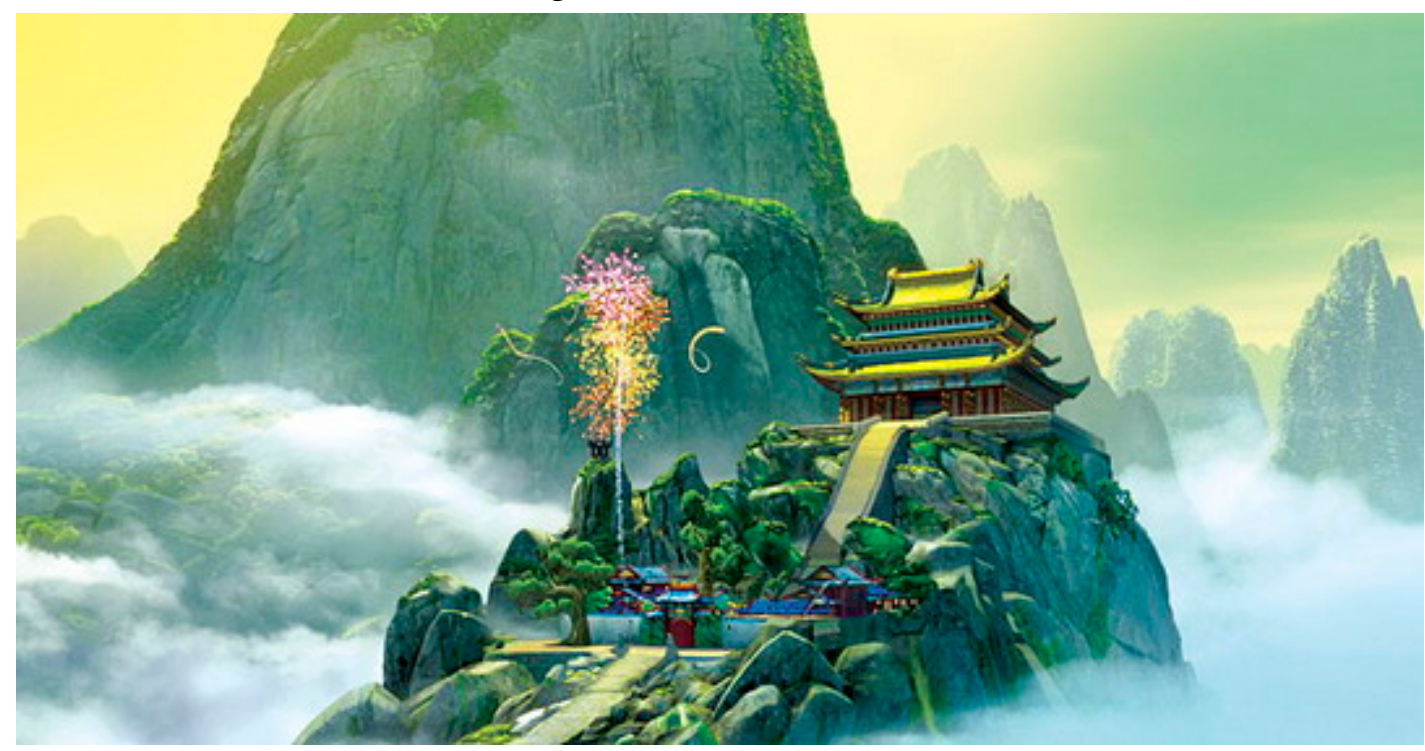

Fig. 1 Emerald palace

\section{The Chinese culture reaction in the film}

The animation image in kungfu Panda contains the cultural symbol of china,the men whose kung-fu in best will be named dragon warrior. In Chinese mythology, the dragon can can make clouds and bring them rain and protect people was given authority, the ancient emperors called themselves the real dragons. emerald palace which in the films has a statue of the dragon, the dragon is one of the most cultural symbol of Chinese national characteristics, Chinese cultural are well reflected in the kungfu Panda. In western culture, the lion is the king of the beasts which reflected in the cartoon The Lion King, but the tiger is the king of beasts in the Oriental culture,the tiger shows wisdom and brave when protection the and also shows the director of China's cultural identity.The five masters whose name is golden monkey, snake spirit, mantis, dumpling tiger represents the five types of Chinese pictographic boxing and five characters embody the different personality,those roles fighting bad guys for the peace of Peace Valley ,it is reflected the Chinese chivalry culture and accordance with Chinese character recognition of these roles.

Chinese Buddhism culture and the Taoist culture is also reflected in the film, the who is the representative figure of Buddha left a deep impression to the audience because his witty language and full of philosophical discourse. master' s word embodies the Chinese buddhist philosophy about causal metempsychosis and decreed by fate. For example, master turtle said: "there is no coincidence." Which means you can't resist the development of things because its cause and effect , at the same time the tortoise master emphasized the power of faith, this is consistent with the theory advocated by the Chinese Buddhism[4]. Taoist culture which reflected in the film is the another representative of the Chinese culture, Such as the Po see the master raccoons control of water 
droplets as he wish and asked him how to do it, the master raccoons said: "as long as could be peace of mind, inner peace is the most beautiful realm in the world." This sentence reflects the Taoist nature and conform to the state of nature.

In addition to this, the Chinese diet culture, festival culture also show incisively and vividly in the film,such as celebrations of master oogway selected the dragon warrior[5].

\section{Chinese culture and Music Design}

Music Design is an important part of the animation design, music can rise to render in the atmosphere, promote the development of the plot, foil the characters and make the film more infectious.The music of kungfu Panda based on Chinese music and integration with western music, Chinese folk music was used when the plot of the film is flat,this way can express the artistic conception to the audience and satisfy the Chinese audience's aesthetic demand, at the same time, the western symphony and pop music was interlude in the film,this formed a unique music characteristic of kungfu Panda.

There are a lot of fighting scenes need cooperate with a strong sense of sound show the power of the kung-fu,for this reason, percussion was used when the rhythm is faster in the fight scenes,at the same time, Chinese traditional music tracks was used,this way makes more tension in fight scene.

\section{Summary}

This article mainly analyzes the application in the animated movie kungfu Panda from the character design, scene design, cultural background, music design ,through the analysis we can see the culture of a nation has a strong influence of animation creation. Chinese culture is the precious wealth accumulated by Chinese people through thousands of years,it is the spirit of the Chinese nation which is still dominant the daily life of Chinese people[6]. In today's globalization, western civilization has already begun to shift attention to the exploration of Chinese culture and make these cultural resources into commercial interests, Compared with Chinese people who live in such a rich cultural atmosphere has a relatively weak consciousness on use of cultural resources, we should learn from the west and carry forward the essence of oriental culture. Although Hollywood animation director exploration the Chinese culture and apply these cultural in animation creation, but their understanding of Chinese culture just on the surface and the understanding of deep Chinese culture still existence error, even though the kung fu panda to use a lot of Chinese culture but the performance is still americans personal heroism and American dream.

We must use rational perspective to look at the American animated cartoon with Chinese culture, we need to study American cartoon creation attitude, on the other hand we must efforts to reverse the strong western culture and carry forward our Chinese traditional culture,work hard for dream of Chinese animation films and let the world understand the deep culture of China.

\section{References}

[1] QingLu.The "experience" performance of the cartoon character.Art Review.2015,No.10,p. 127-129.

[2] Jun Fan.Analysis on the storyboard of animation.Home of drama.2014,No. 8, p. 218-219.

[3] Kang Kang.Talking about the animation performance.Art Education Research,2015,No.5,p. 83-84.

[4] Peng Chen .Effects of characteristic motions in animation film.Movie iterature.2015,No.3,p. 83-85.

[5] JianWu.Discussion in action design of animation role performance. Art Criticism,.2013,No.3,p. 13-116.

[6] Haoquan Teng.Discussion on the influence of role modeling design on character shaping. Film Review.2011,No.1,p. 15-16. 